TITLE:

\title{
Interface crack initiation due to nano-scale stress concentration
}

\author{
$\operatorname{AUTHOR}(S)$ : \\ Sumigawa, Takashi; Shishido, Tetsuya; Murakami, \\ Tadashi; Kitamura, Takayuki
}

\section{CITATION:}

Sumigawa, Takashi ...[et al]. Interface crack initiation due to nano-scale stress concentration. Materials Science and Engineering: A 2010, 527(18-19): 4796-4803

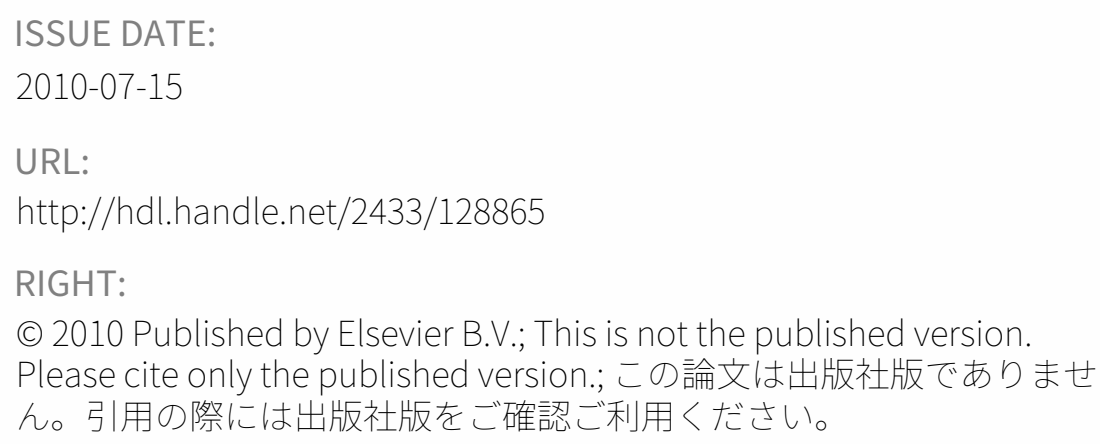




\title{
Interface Crack Initiation Due to Nanoscale Stress Concentration
}

Authors: Takashi Sumigawa ${ }^{1 *}$, Tetsuya Shishido ${ }^{1}$, Tadashi Murakami ${ }^{1}$, and Takayuki Kitamura $^{1}$

Affiliations:

1 Department of Mechanical Engineering and Science, Kyoto University, Kyoto 606-8501, Japan

*Corresponding author

Keywords:

Nanoscale, Interface, Crack, Initiation, Stress concentration, Thin film

\begin{abstract}
In order to investigate the mechanical factors dominating interfacial crack initiation in nanometer-scale components, we prepared two types of specimens containing an interface between a 20 -nm-thick copper $(\mathrm{Cu})$ thin film and a silicon $(\mathrm{Si})$ substrate. In one specimen, the stress concentration was at the interface edge, while in the other specimen, it was in the interior. In the former, a crack was initiated at the $\mathrm{Cu} / \mathrm{Si}$ interface edge under a stress concentration of about $1 \mathrm{GPa}$ extending over 20 - 30 $\mathrm{nm}$. In the latter, using a cantilever specimen with a step, a crack was initiated in the interior at the $\mathrm{Cu} / \mathrm{Si}$ interface at a stress concentration of about $1 \mathrm{GPa}$ extending over 60 $\mathrm{nm}$, which coincides fairly well with that at the interface edge. These results demonstrate the applicability of a unified criterion for interface crack initiation, though the interior is slightly more resistant to cracking.
\end{abstract}


Nomenclature

\begin{tabular}{|c|l|}
\hline symbol & \multicolumn{1}{|c|}{ signification } \\
\hline FIB & focused ion beam \\
\hline TEM & electron beam \\
\hline SEM & scanning electron microscopy \\
\hline FEM & finite element method \\
\hline$l_{1}$ & $\begin{array}{l}\text { length from the root of the cantilever to the } \mathrm{Cu} / \mathrm{Si} \\
\text { interface }\end{array}$ \\
\hline$l_{2}$ & $\begin{array}{l}\text { length from the } \mathrm{Cu} / \mathrm{SiN} \text { interface to the edge of the } \\
\text { cantilever }\end{array}$ \\
\hline$h$ & height of cantilever \\
\hline$w$ & width of cantilever \\
\hline$t$ & thickness of Cu thin film \\
\hline$\sigma_{\mathrm{y}}$ & yield stress \\
\hline$\sigma_{\mathrm{Cu}}$ & residual stress of Cu thin film \\
\hline$\sigma_{\mathrm{SiN}}$ & residual stress of SiN layer \\
\hline$P_{\mathrm{c}}$ & critical load for fracture \\
\hline$\sigma^{*}$ & arbitrary stress in stress-displacement curve \\
\hline$r^{*}$ & $\begin{array}{l}\text { breath of stress-displacement curve corresponding to } \\
\sigma^{*}\end{array}$ \\
\hline & \\
\hline
\end{tabular}




\section{Introduction}

Interfaces are one of the most favorable potential crack initiation sites in micro- and nano-scale components because they often have weak bonding (low resistance to fracture) and stress concentration (high driving force for fracture) due to the deformation mismatch of dissimilar materials $[1,2]$. Because an interface edge, where an interface meets the surface, often has a stress singular field, it can be a highly probable site of crack initiation [3-5]. Thus, much research [6-13] has been conducted on interface cracking due to the stress intensity. We have experimentally explored the mechanical behavior of cracks at the interface edge on the nanometer scale [14-17]. Previous work [17] revealed that the stress-concentration region about $50 \mathrm{~nm}$ from the interface edge, which corresponds to about 150 atoms, governed the crack initiation, which indicates that the continuum mechanics concept is applicable, even on the nano-scale, and can describe fracture characteristics. However, it is not clear that the concept is applicable to smaller regions of stress concentration in terms of the local interface fracture.

In general, stress concentration does not always take place at the edge or at the crack tip because nano-components are often composed of multi-layered materials with complex shapes. Because the edge has a peculiar atomic arrangement, it is expected to have some resistance to fracture in comparison to an internal interface, which suggests that interface crack initiation is dependent upon the location in the component. Because the stress is usually concentrated near the interface edge in a simply shaped sample under a simple load, it is relatively easy to conduct a crack initiation experiment. However, it is difficult to introduce a designed stress concentration at an interface, except at the edge. Thus, although nanoscale cracking is very important for the reliability of nano-devices, it has not yet been explored in depth.

In this study, we conduct experiments on crack initiation using two types of specimens that have stress concentrations within a few tens of nano-meters at two different locations, the interface edge and the interior. Additionally, we also investigate the criteria using the experimental results.

\section{Crack Initiation at an Interface Edge}

\subsection{Experimental Procedure}

The material examined was a multilayer copper $(\mathrm{Cu})$ (thickness: $20 \mathrm{~nm}$ ) and silicon nitride (SiN) (thickness: $500 \mathrm{~nm}$ ) sample, deposited on a silicon ( $\mathrm{Si})(100)$ wafer by magnetron sputtering at rates of 24 and $10.5 \mathrm{~nm} / \mathrm{min}$, respectively, under a chamber pressure of $0.67 \mathrm{~Pa}$. 
Figure 1(a) schematically illustrates the specimen and the loading scheme for the investigation of cracking behavior at the $\mathrm{Cu} / \mathrm{Si}$ interface edge. The specimen was carved from the multilayered material by focused ion beam (FIB) processing, as described in the next paragraph, and the load was applied to the $\mathrm{SiN}$ layer away from the $\mathrm{Cu} / \mathrm{Si}$ interface. Figure 1(b) shows a schematic illustration of the stress distribution along the $\mathrm{Cu} / \mathrm{Si}$ interface where a crack is expected to appear at the interface edge because of the stress concentration.

Before sample fabrication, gold $(\mathrm{Au})$ was deposited on the $\mathrm{SiN}$ layer to protect the specimen from the damage during processing. A $10 \times 10 \times 10 \mu \mathrm{m}^{3}$ block was carved from the multilayer material using FIB (Fig. 2 (a)) and was then picked up by a glass probe (Fig. 2 (b)). After the block was mounted to a Au wire $(\varphi 0.25 \mathrm{~mm})$ with a flat top using an adhesive (Fig. 2 (c)), a cantilever-shaped specimen containing the $\mathrm{Cu} / \mathrm{Si}$ interface was processed by FIB at a power of $30 \mathrm{kV}$ and a current of $10 \mathrm{nA}$ (Fig. 2 (d)). The surfaces were finished by removing a damaged layer about $20 \mathrm{~nm}$ thick, and the shape near the interface edge was adjusted by FIB at a power of $30 \mathrm{kV}$ and a current of $10 \mathrm{pA}$.

The TEM micrograph of the specimen shown in Fig. 3 shows no cracking and no damage near the $\mathrm{Cu} / \mathrm{Si}$ interface. Three specimens (Specimens 1, 2, and 3) of different sizes, as summarized in Table 1, were prepared. 


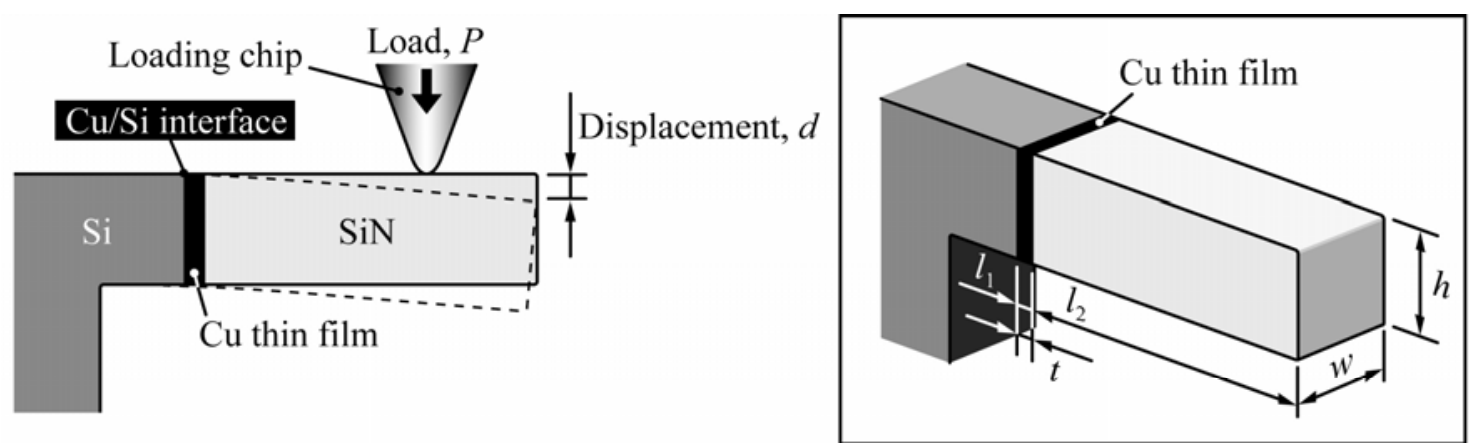

(a)

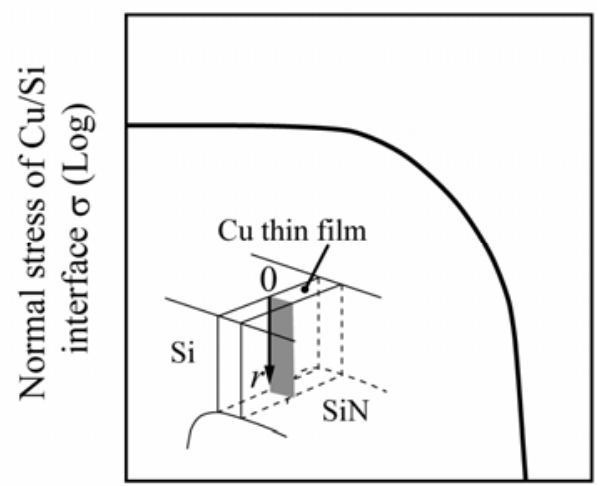

Distance from interface edge $r(\log )$

(b)

Fig. 1 Experimental specimen and loading method for crack initiation at the $\mathrm{Cu} / \mathrm{Si}$ interface edge.

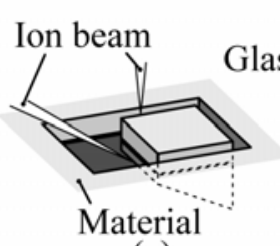

(a)

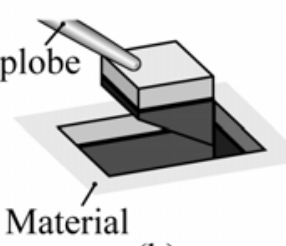

(b)

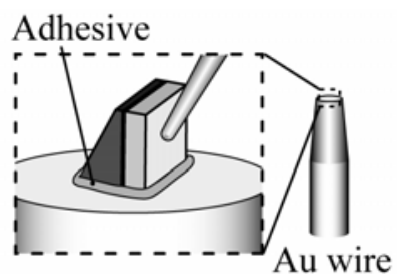

(c)

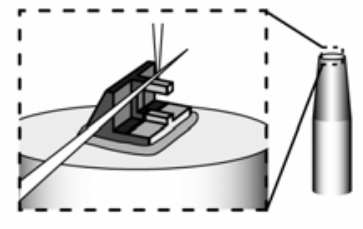

(d)

Fig. 2 Schematic illustration of the preparation procedure of a nanoscale cantilever specimen. 


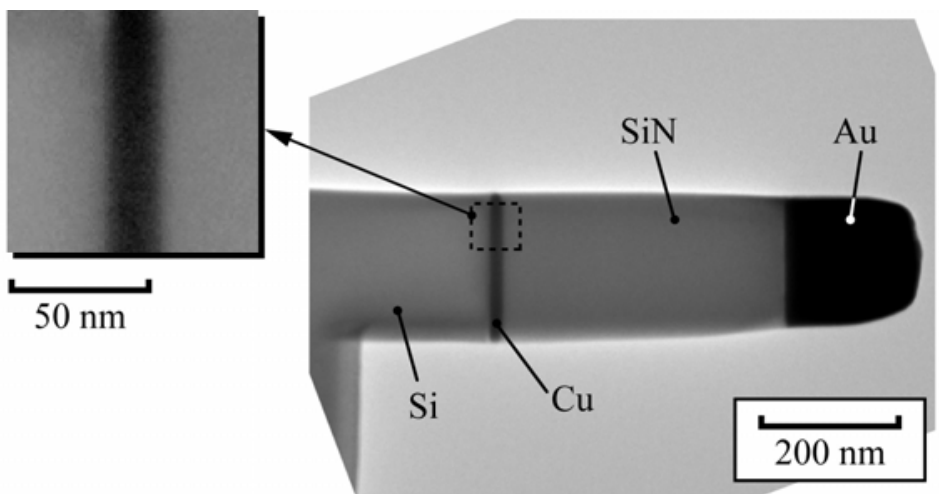

Fig. 3 TEM image of a specimen (Specimen 1).

Table 1 Specimen sizes. Dimensions are in $\mathrm{nm}$.

\begin{tabular}{|c|c|c|c|c|c|}
\hline & $l_{1}$ & $l_{2}$ & $h$ & $w$ & $t$ \\
\hline Specimen 1 & 220 & 715 & 250 & 434 & 20 \\
\hline Specimen 2 & 120 & 700 & 233 & 308 & 20 \\
\hline Specimen 3 & 84 & 767 & 642 & 415 & 20 \\
\hline
\end{tabular}

Figure 4 shows the loading apparatus, which was composed of a stage with mobility in three orthogonal directions driven by piezo actuators and a diamond tip with a load sensor. The measurement range and accuracy of the loading were $0-100 \mu \mathrm{N}$ and $\pm 0.1 \mu \mathrm{N}$, respectively. The Au wire with the specimen was attached to the stage, and the load was applied by pushing it against the tip at a stage velocity of $8 \mathrm{~nm} / \mathrm{s}$. In order to observe the cracking behavior, the experiment was conducted in a transmission electron microscope (TEM) at an accelerating voltage of $200 \mathrm{kV}$ under vacuum $\left(1.5 \times 10^{-5} \mathrm{~Pa}\right)$. The interface and the loading point were clearly identified by TEM, but the observation of dislocations was outside in the scope of this project.

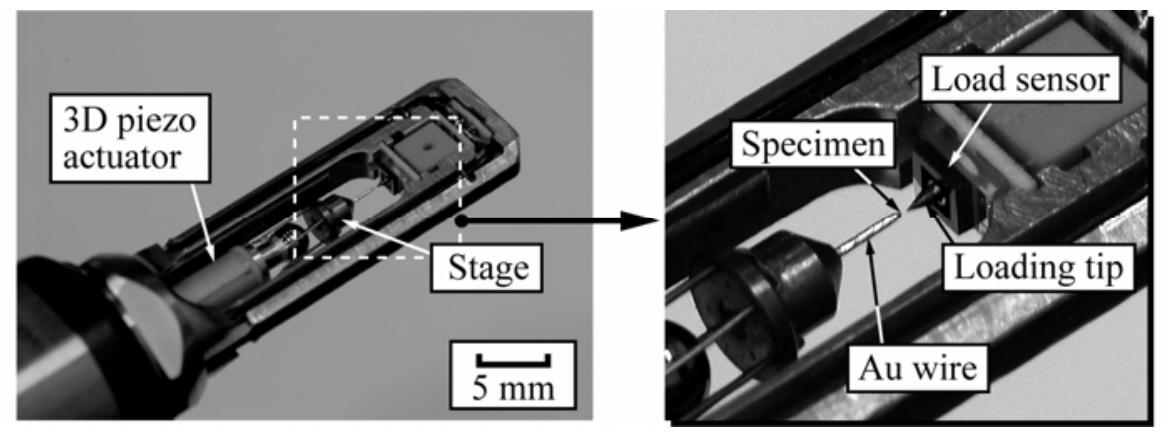

Fig. 4 Loading apparatus used in the interface cracking experiment with a nanoscale specimen. 


\subsection{Analytical procedure}

The stress in the specimen was analyzed by the finite element method (FEM), in which an individual model was prepared for each experimental specimen. Figure 5 shows the analytical model of Specimen 1, in which the configuration is reconstructed using three-dimensional CAD (computer aided design system) software on the basis of the geometry measured, which was precisely obtained by $3 \mathrm{D}$ analysis of scanning electron microscope (SEM) and TEM micrographs. The region near the $\mathrm{Cu} / \mathrm{Si}$ interface, where stress concentration is expected, was divided into a finer mesh. A perfect constraint condition was imposed on the back and the bottom ends of the model.

Table 2 Elastic constants in FEM analysis.

\begin{tabular}{|c|c|c|}
\hline Material & $\begin{array}{c}\text { Young's modulus } \\
(\mathrm{GPa})\end{array}$ & Poisson's ratio \\
\hline $\mathrm{Cu}$ & 129 & 0.34 \\
\hline $\mathrm{SiN}$ & 197 & 0.27 \\
\hline $\mathrm{Au}[18]$ & 78 & 0.44 \\
\hline
\end{tabular}

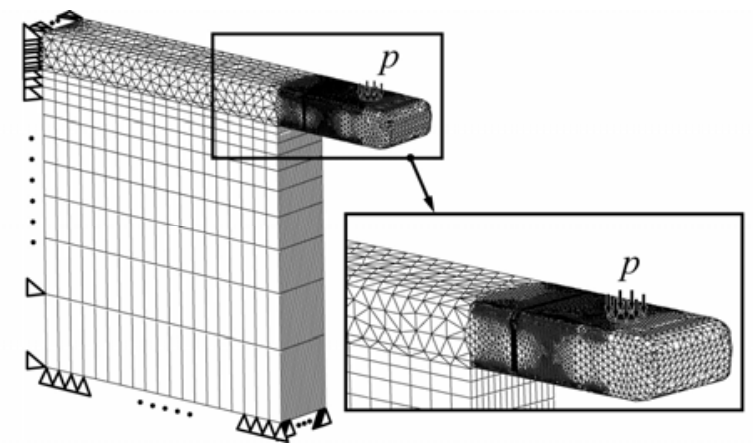

Fig. 5 Mesh division in FEM analysis (Specimen 1).

The Si substrate was treated as an orthotropic elastic material, because it was a single crystal. The Young's modulus of the SiN layer, which could affect the stress condition of the $\mathrm{Cu} / \mathrm{Si}$ interface, was measured by an indentation test. The elastic constants of the component materials are summarized in Table 2. Because the yield stress of the $\mathrm{Cu}$ thin film was much lower than those of the Si substrate $\left(\sigma_{\mathrm{y}}>3.4 \mathrm{GPa}\right.$ [19]) and $\mathrm{SiN}$ layer $\left(\sigma_{\mathrm{y}}>8.4 \mathrm{GPa}[20]\right)$, the $\mathrm{Cu}$ thin film was considered to be elasto-plastic in these experiments. The constitutive equation, which was experimentally obtained in our previous paper [21], is given as follows:

$$
\sigma=\left\{\begin{array}{l}
129000 \varepsilon \quad \text {, for } \quad \sigma \leq 765(\mathrm{MPa}) \\
3316 \varepsilon^{0.332}, \text { for } \quad \sigma \geq 765(\mathrm{MPa})
\end{array} .\right.
$$


where $\sigma$ and $\varepsilon$ are the von Mises stress and strain, respectively.

Deposited thin films generally contain residual stresses due to thermal expansion coefficient differences and peculiar atomic arrangements. The residual stresses of the $\mathrm{Cu}$ thin film and the SiN layer were measured experimentally in a previous paper $\left(\sigma_{\mathrm{Cu}}=\right.$ $760 \mathrm{MPa}$ and $\sigma_{\mathrm{SiN}}=-300 \mathrm{MPa}$ [21]). After these were imposed upon the cantilever model, it was relaxed. Then, the distributed load, $p$, was introduced to the SiN layer of the relaxed cantilever.

\subsection{Experimental Results}

Figure 6(a) shows the loading curve $(P-t)$ of Specimen 1. The load, $P$, monotonically increased up to a peak magnitude of $16.9 \mu \mathrm{N}$ (point $\mathrm{b}$ ) and then abruptly dropped to $0 \mu \mathrm{N}$ (point c). Figure 6(b) shows TEM micrographs corresponding to the points $\mathrm{a}, \mathrm{b}$ and $\mathrm{c}$ on the $P$ - $t$ curve. No crack initiation was recognized before the peak load, when the $\mathrm{Cu} / \mathrm{Si}$ interface was delaminated. In other words, the crack initiated at the point $b$ at the top interface edge and instantly propagated along the interface. Detailed observation after the experiment demonstrates that no dissimilar material remained on either delaminated plane, confirming pure interface-cracking. Similar behavior was observed in Specimens 2 and 3. Thus, the peak loads for interfacial crack initiation, $P_{\mathrm{c}}$, is defined as the critical load, and Table 3 lists the magnitudes of $P_{\mathrm{c}}$. There are significant differences in $P_{c}$ among the specimens. 


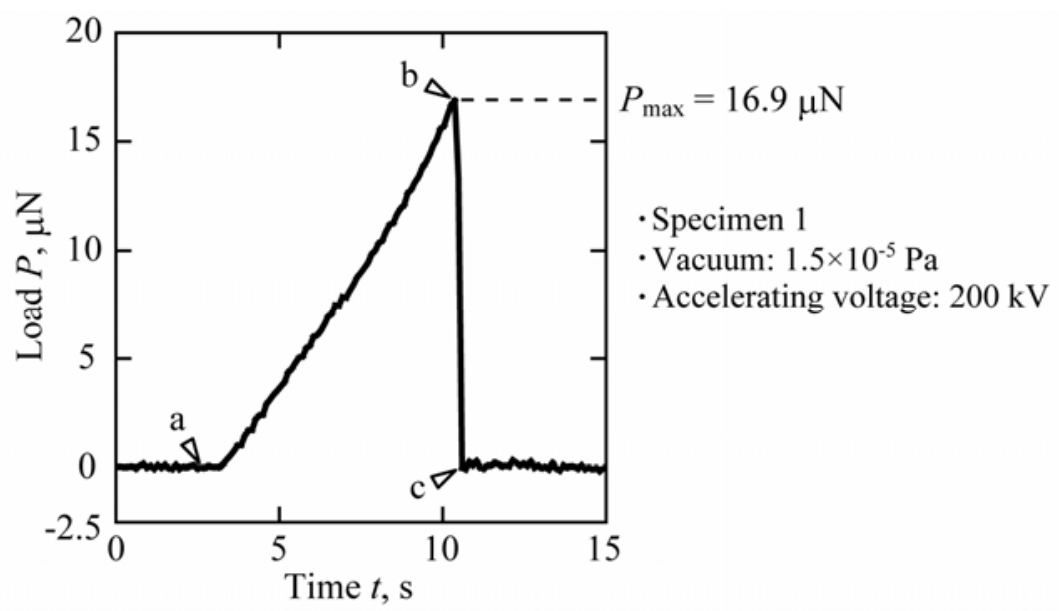

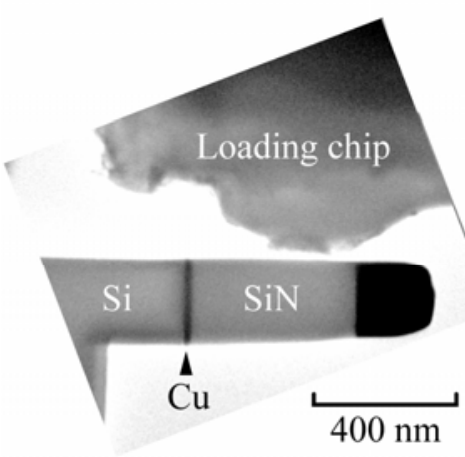

a

(a)

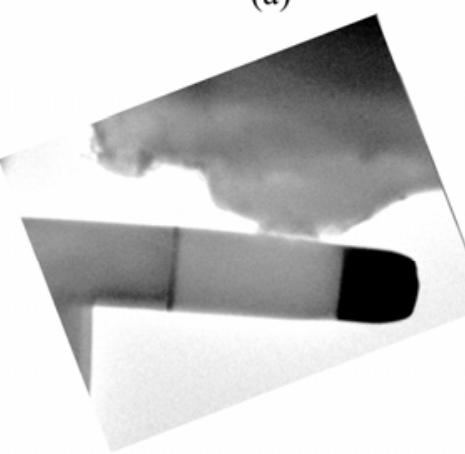

b

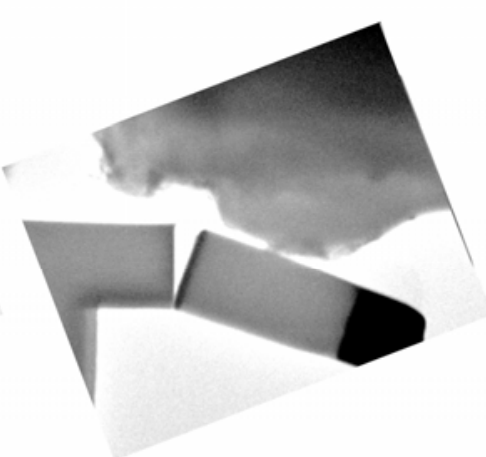

$\mathrm{c}$

(b)

Fig. 6 Load-time relationship and in situ observation of the interfacial fracture of Specimen 1.

Table 3 Critical load for crack initiation at the interface edge.

\begin{tabular}{|l|c|}
\hline & $P_{\mathrm{C}}(\mu \mathrm{N})$ \\
\hline \hline Specimen 1 & 16.9 \\
\hline Specimen 2 & 10.3 \\
\hline Specimen 3 & 85.3 \\
\hline Specimen 4 & 29.6 \\
\hline
\end{tabular}

\subsection{Critical Nano-scale Stress Concentration}

Figure 7 shows the distribution of normal and shear stresses, $\sigma$ and $\tau$, along the $\mathrm{Cu} / \mathrm{Si}$ interface near the edge at the critical load, $P_{\mathrm{c}}$. Although the stresses away from the edge differ from each other, they show good agreement near the edge. This agreement indicates that crack initiation is governed by the concentrated stress. The normal stress distribution near the interface edge resulted in a high stress of about $1 \mathrm{GPa}$, 
which is approximately three-times that of the shear stress $(\tau \approx 300 \mathrm{MPa})$. Thus, the normal stress dominates the cracking behavior in these cases. The region in which the normal stress distribution agrees is $r<20-30 \mathrm{~nm}$. In our previous work [17], a similar experiment was conducted for the $\mathrm{Cu} / \mathrm{Si}$ interface, in which the $\mathrm{Cu}$ film was $200 \mathrm{~nm}$ thick. That work revealed that a concentrated stress of about $1 \mathrm{GPa}$ in the region of $r<$ $50 \mathrm{~nm}$ can cause the crack initiation at the interface edge. Figure 7(a) demonstrates that a smaller region of $r<20-30 \mathrm{~nm}$ can produce local fracture via interface crack initiation.

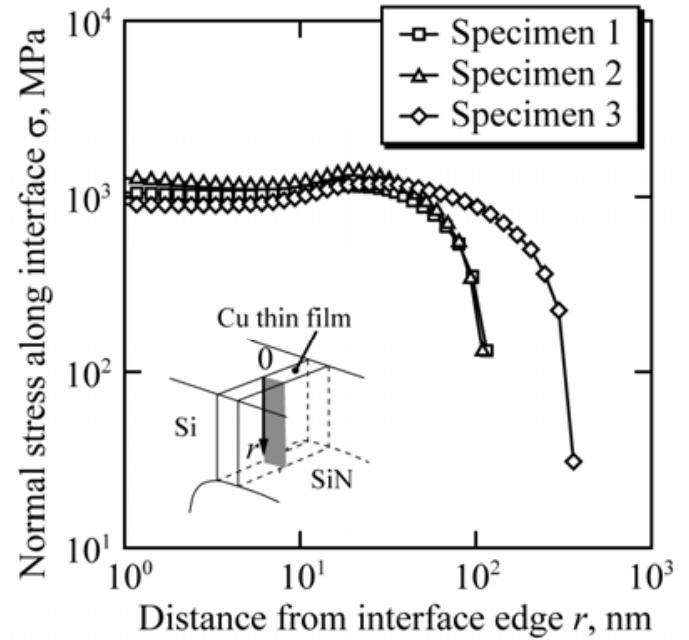

(a)

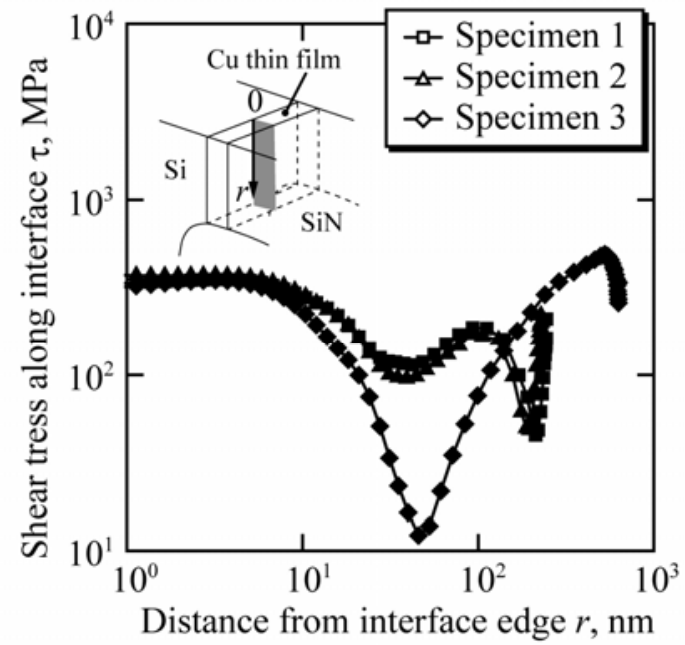

(b)

Fig. 7 Elasto-plastic stress distributions along the $\mathrm{Cu} / \mathrm{Si}$ interface near the edge: (a) normal stress $\sigma$, (b) shear stress, $\tau$.

\section{Interfacial Crack Initiation in the Interior}

\subsection{Experimental and Analytical Procedure}

Figure 8 shows the dimensions of a specimen (Specimen 4) with a step in the SiN layer. Under vertical loading, no stress concentration developed at the interface edge, and the stress had a maximum in the central region of the $\mathrm{Cu} / \mathrm{Si}$ interface. This stress distribution suggested that an interfacial crack initiation in the specimen would occur.

The specimen was carved from the multilayer material by FIB processing, and a load was applied using the apparatus described in Section 2. FEM analysis with the influence of residual stress was conducted under conditions similar to those in Section 2. Figure 9 shows the analytical model, in which the specimen configuration was reconstructed on the basis of detailed SEM and TEM observations. 

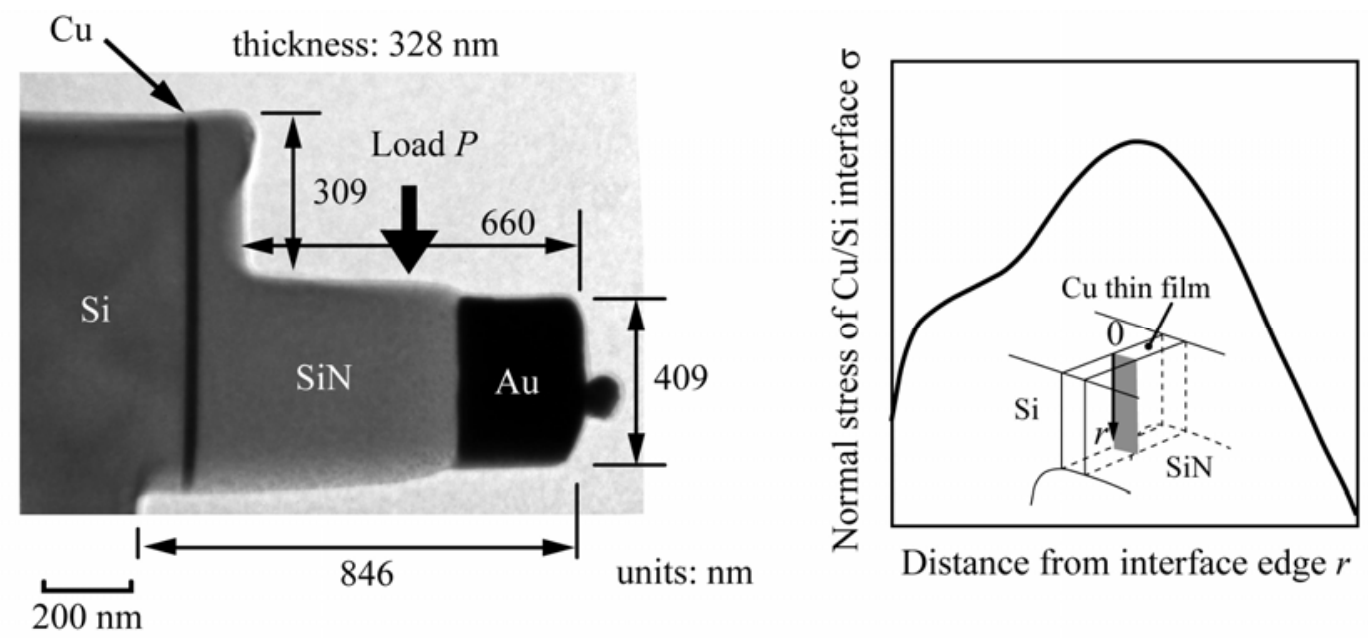

Fig. 8 TEM image of specimen (Specimen 4) and the stress distribution along the $\mathrm{Cu} / \mathrm{Si}$ interface.

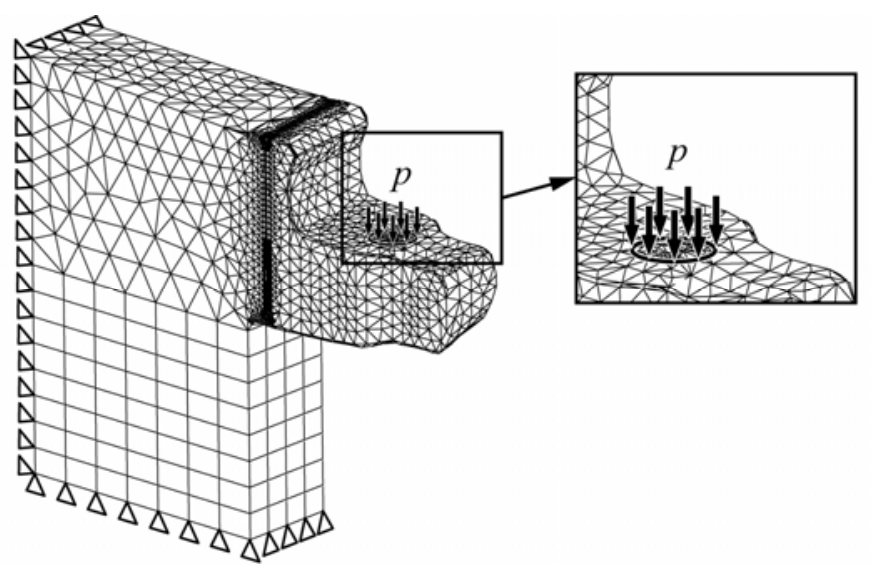

Fig. 9 Mesh division of Specimen 4, which has a crack at the $\mathrm{Cu} / \mathrm{Si}$ interface.

\subsection{Experimental Results}

Figure 10(a) shows the $P$-t relationship for Specimen 4. $P$ monotonically increased up to $P=54.3 \mu \mathrm{N}$ (point $\mathrm{C}$ ), and the load remained briefly constant. Then, the load began to increases again (point D), before sharply dropping at the point E. Figure 10(b) shows sequential TEM micrographs corresponding to the above labeled points on the $P$ - $t$ curve. The interface was suddenly bent, and a crack, which looks like a white area in the center photo in Fig. 10 (b), appeared at the point C, the location of which is about $r=300 \mathrm{~nm}$ from the interface edge on the upper surface (See Fig. 10(c)).) Because the specimen possessed a sufficient width and the $\mathrm{Si} / \mathrm{Cu}$ interface was brittle $[13,14]$, local buckling and plastic collapse did not takes place. Finally, the crack stopped growing until point $\mathrm{E}$ and then instantaneously propagated along the interface. 
Figure 11 shows the relationship between the applied load and the displacement at the arm end, where the displacement was measured using TEM images during the experiment. The displacement jumped at the point $\mathrm{C}$, when crack initiation was observed. After point D, although the load increased again, the compliance between D and $\mathrm{E}$ was lower than that between $\mathrm{B}$ and $\mathrm{C}$. This result indicates that the specimen stiffness was lower between $\mathrm{C}$ and $\mathrm{E}$ due to the appearance of an interfacial crack.

It was extremely difficult to specify the precise location of the crack tip by TEM observation. Therefore, the crack length was roughly estimated by FEM analysis on the basis of the load-displacement curve after point D. An interfacial crack of different length was introduced in the FEM model at $300 \mathrm{~nm}$ from the interface edge on the upper surface, and the calculations were performed. Considering the displacement, the interfacial crack was evaluated to be $L \approx 300 \mathrm{~nm}$. Because this value is a rough approximation that ignores the plasticity before the cracking and other factors, further consideration was required in order to apply these results to the detailed estimation of the fracture toughness of the interface at $E$. 


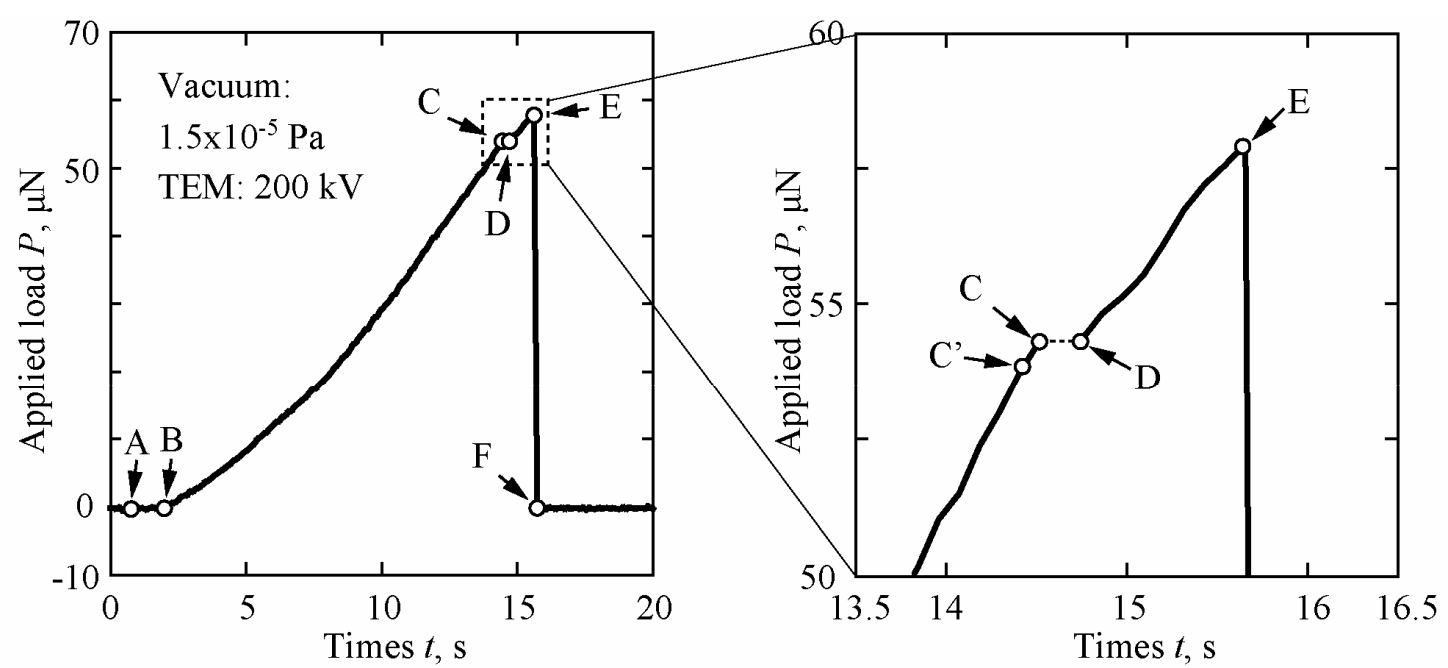

(a)
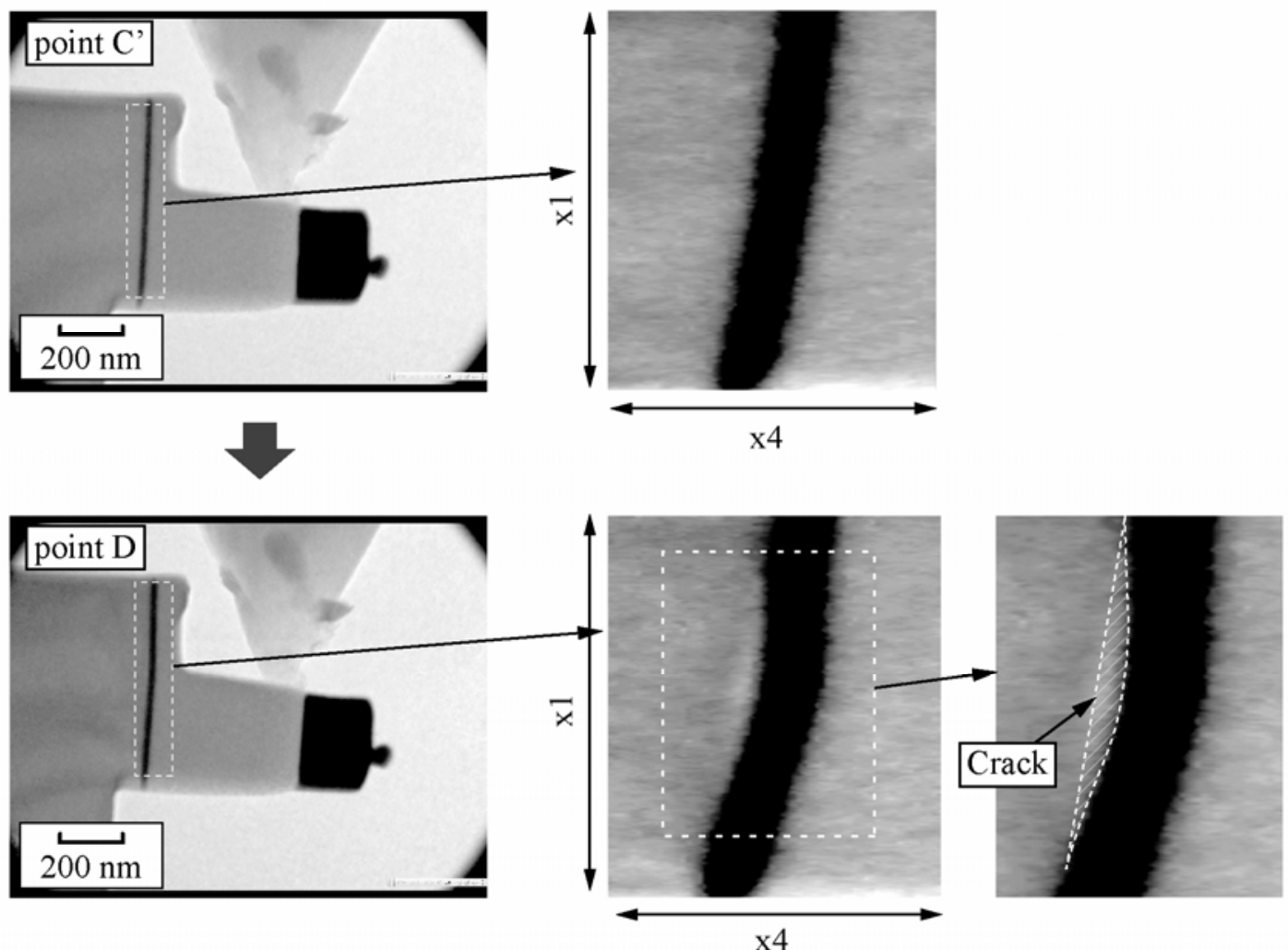

(b)

Fig. 10 (a) Load-time relationship of Specimen A and (b) detailed TEM images near the moment of crack initiation. 


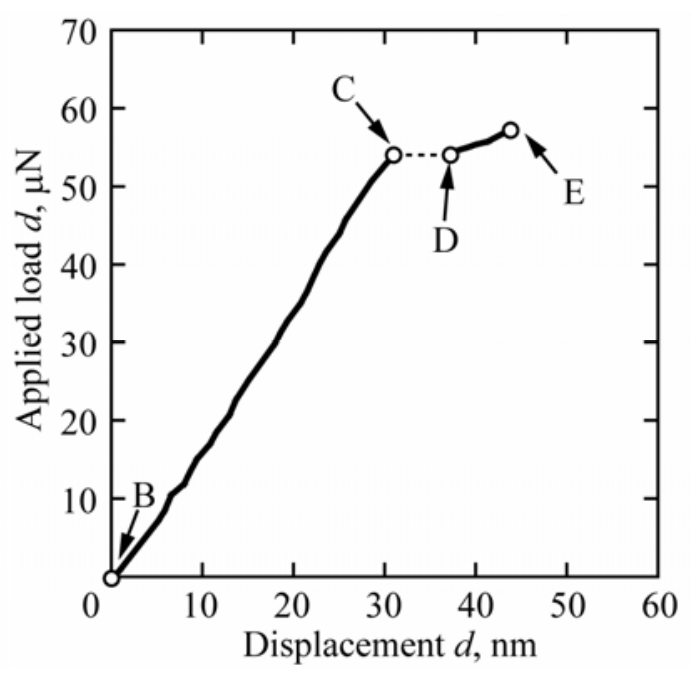

Fig. 11 Load-displacement relationship.

\subsection{Dominant Stress at Crack Initiation}

Figure 12(a) shows the distributions of normal stress, $\sigma$, and shear stress, $\tau$, along the $\mathrm{Cu} / \mathrm{Si}$ interface. Although there was no high concentration of stress near the interface edge, $\sigma$ had a peak concentration at $r \approx 300 \mathrm{~nm}$, which corresponds to the experimentally observed position of crack initiation. Because $\sigma$ at $r=300 \mathrm{~nm}$ was much larger than that of $\tau$, the former was dominant in the crack initiation. Figure 12(b) shows a magnified view of the $\sigma$-distribution near $r=300 \mathrm{~nm}$. The maximum stress was about $1.1 \mathrm{GPa}$, and the region of $\sigma>1 \mathrm{GPa}$ extended to about $60 \mathrm{~nm}$.

In Section 2, we indicated out that the crack initiation at the interface edge was governed by the normal stress of about $1 \mathrm{GPa}$ extended to about $30 \mathrm{~nm}$ (Fig. 7(a)). Comparing the results shown in Figs. 7(a) and 12(b), crack initiation in the interior had the following characteristics:

(1) The critical stresses in both cases were of almost the same magnitude, about 1 GPa.

(2) The high-stress regions in both cases were several tens of nanometers in width, but the interior crack initiation required a slightly wider region.

In short, there is little difference between the crack initiation criteria along the interface at the edge and in the interior.

As schematically illustrated in Fig. 13(a), we define the curve breadth, $r^{*}$, for arbitrary $\sigma^{*}$ in Fig. 12(b). The symbols $\bullet$ in Fig. 13(b) show the $\sigma^{*}-r^{*}$ relation extracted from Fig. 12(b), which presents the extent of the high-stress region at the criterion. The relation begins at $\left(\sigma^{*}, r^{*}\right)=(1.1 \mathrm{GPa}, 0 \mathrm{~nm})$ and extends through $(1 \mathrm{GPa}, 60 \mathrm{~nm})$. In the figure, the symbols $\circ$, indicate the critical (average) stress field at crack initiation from 
the edge, as shown in Fig. 7(a). The former $(\bullet)$ coincides fairly well the latter $(\circ)$. In these experiments, the specimens (Specimen 1 to 4 ) were designed to have a similar extent of concentrated stress as shown in the figure. In other words, we examined the critical stress level (interface resistance for crack initiation) under the same extent of concentrated stress (driving force for crack initiation). The coincidence between $\circ$ and $\bullet$ clearly demonstrates that the unified criterion can be applied to interface cracking, both at the edge and in the interior. This result implies that the edge does not have a strong influence on the resistance to interfacial crack initiation.

The specimen illustrated in Fig. 14(a) has a sharp stress peak, as schematically presented in Fig. 14(b). Because the criterion must be dependent on not only the highest stress but also on the extent of high stress, we can expect that a smaller area governs the crack initiation. In order to seek a general criterion for interior cracking, we can discuss it on the basis of the $\sigma^{*}-r^{*}$ relation with a steep distribution (--- (broken line)) as shown in Fig. 14(c), and the $\sigma-r$ relation for the crack initiation at the interface edge (- (solid line)) obtained from the specimen with a notch at the edge (Fig. 14(c)). 

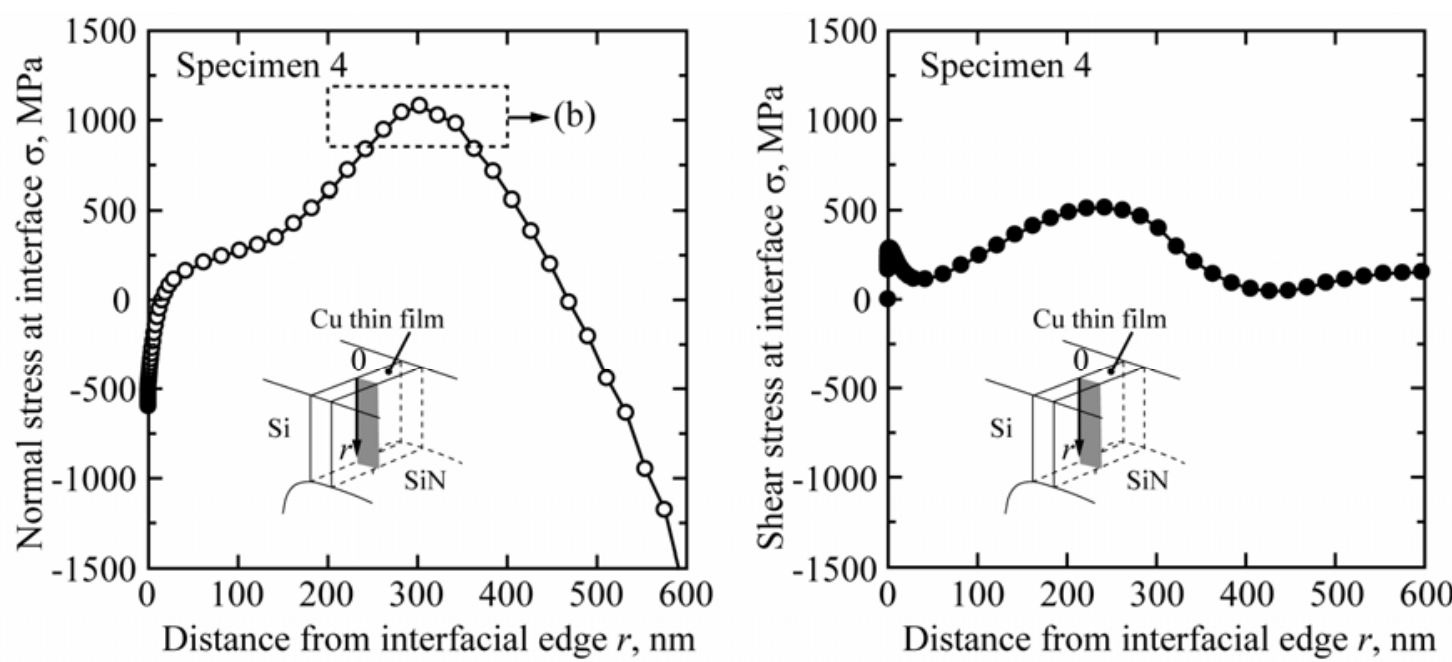

(a)
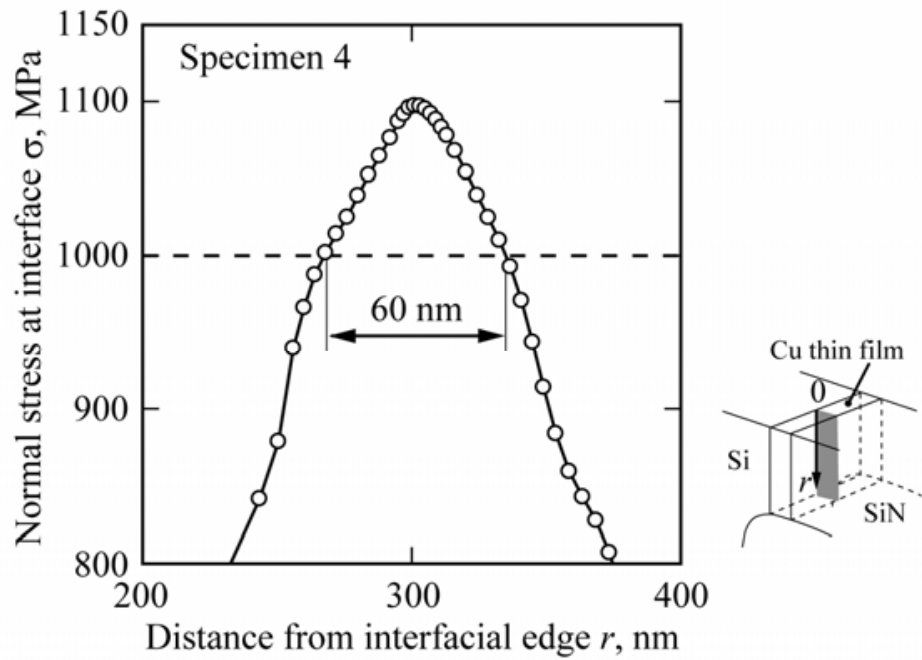

(b)

Fig. 12 Stress distributions along the $\mathrm{Cu} / \mathrm{Si}$ interface. 


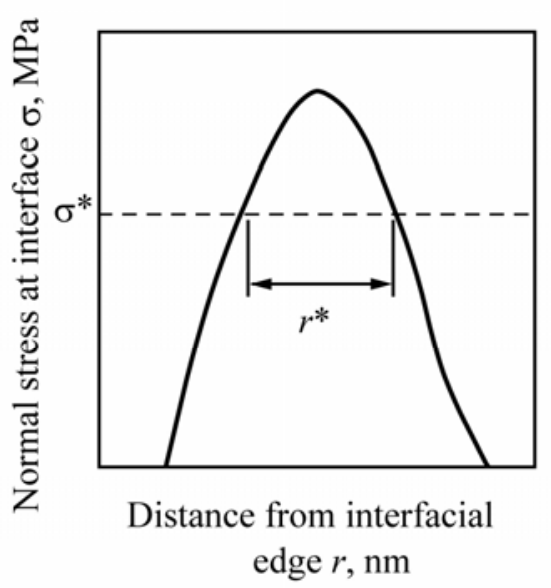

(a)

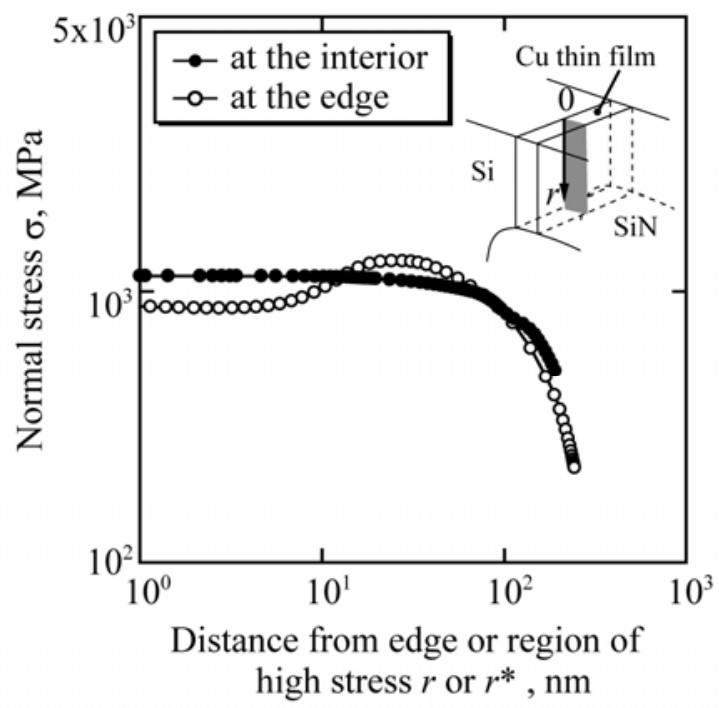

(b)

Fig. 13 Stress distributions along the $\mathrm{Cu} / \mathrm{Si}$ interface.

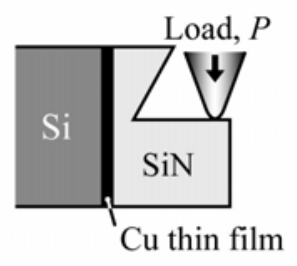

(a)

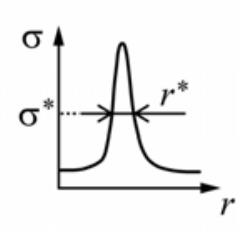

(b)

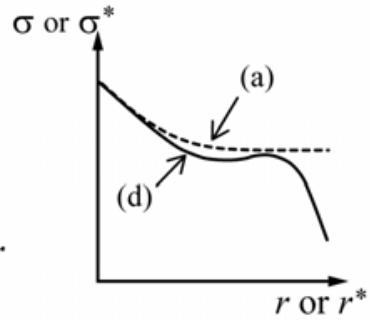

(c)

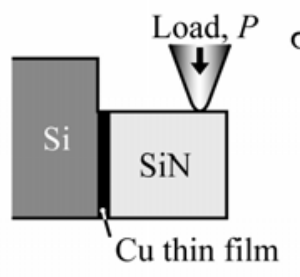

(d)

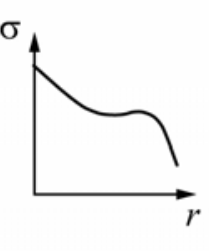

Fig. 14 Schematic illustrations of specimens and the stress distributions at the interface.

\section{Conclusion}

In order to investigate the factors that govern interfacial crack initiation at the edge and in the interior, we conducted mechanical experiments using specimens with stress concentrations on the nanometer scale at the interface between a 20 -nm-thick $\mathrm{Cu}$ thin film and a Si substrate. The results are described as follows:

1. In the cantilever specimens shown in Fig. 1, a crack was initiated at the $\mathrm{Cu} / \mathrm{Si}$ interface edge where the stress was concentrated. The crack instantaneously propagated along the $\mathrm{Cu} / \mathrm{Si}$ interface. The normal stress of the interface dominated the crack initiation. A stress concentration of about $1 \mathrm{GPa}$ in the region of $r<20 \mathrm{~nm}-30 \mathrm{~nm}$ caused crack initiation at the interface edge.

2. In an experiment using a cantilever specimen with a step in the SiN layer, as shown in Fig. 8, a crack was initiated at the interior $\mathrm{Cu} / \mathrm{Si}$ interface of the specimen, where the concentrated stress was about $1 \mathrm{GPa}$ in the region of $r^{*}<60$ $\mathrm{nm}$. After the crack initiation, the crack briefly stopped growing (pre-crack) and 
then resumed propagation after a load increase. The length of the pre-crack was analytically estimated to be about $300 \mathrm{~nm}$.

3. The critical stress and the extent of stress concentration in 1 (crack initiation at the interface edge) and 2 (crack initiation in the interior) coincide very well, as shown in Fig. 13 (b). This indicates that the interface edge does not have a strong influence on the resistance to interface crack initiation. Thus, a unified criterion can be applied to interfacial crack initiation, both at the edge and in the interior.

\section{Acknowledgments}

This paper was supported in part by a Grant-in-Aid for Scientific Research (S)(No.21226005) from the Japan Society of the Promotion of Science and by a Grant-in-Aid for Young Scientists (A)(No. 21686013) from the Ministry of Education, Culture, Sports, Science and Technology, Japan. 


\section{References}

[1] Bogy DB. J Appl Mech 1968;35:460.

[2] Bogy DB. J Appl Mech 1971;38:377.

[3] Labossiere PEW, Dunn ML Journal of Mechanics and Physics of Solids 2001;49:609.

[4] Reedy Jr. ED, Guess TR International Journal of Solids and Structures, 1993;30:2929.

[5] Fan XJ, Wang HB, Lim TB IEEE Transactions on Components and Packaging Technologies 2001;24:84.

[6] Buchwalter LP VSP, Netherlands 2001;2:19.

[7] Bagchi A, Lucas GE, Suo Z, Evans AG J Mater Res 1994;9(7):1734.

[8] de Boer MP, Kriese MD, Gerberich WW J Mater Res 1997;12(10):2673.

[9] Rossington C, Evans AG, Marshall DB J Appl Phys 1984;56(10):2639.

[10] Takahashi H, Kamiya S, Saka M, Abe H Diamond Related Mater 2001;10:760.

[11] Marshall DB, Evans AG J Appl Phys 1984;56:2632.

[12] Kitamura T, Hirakata H, Van Truong D Thin Solid Films 2007;515:3005.

[13] Kitamura $\mathrm{T}$, Hirakata $\mathrm{H}$, Itsuji $\mathrm{T}$ Engineering Fracture Mechanics 2003;70:2089.

[14] Hirakata H, Takahashi Y, Matsumoto S, Kitamura T Eng. Frac. Mech. 2006;73:2698.

[15] Hirakata H, Kitamura T, Yamamoto Y Int. J. Solid and Structures 2004;41:3243.

[16] Takahashi Y, Hirakata H, Kitamura T Thin Solid Films 2008;516:1925.

[17] Hirakata H, Takahashi Y, Van Truong D, et al. Int. J. Frac. 2007;145:261-271.

[18] Tokyo Astronomical Observatory, ed., "Rika Nenpyo" ("Science Almanac"), Maruzen, physcal chemistry part 1979;24

[19] NiX. WD Metallurgical and Materials Transactions 1989;20:2217.

[20] Lee KS, Wuttiphan S, Hu XZ, Lee SK, Lawn BR Journal of the American Ceramice Society 1998;81:571.

[21] Sumigawa T, Shishido T, Murakami T, Iwasaki T, Kitamura T Thin Solid Films, submitted. 